\title{
The possibility of studying the structural changes associated with socio-economic crises in the results of testing of student-managers
}

\author{
Vladimir F. Tarasenko \\ Tomsk State University, TSU \\ Tomsk, Russia \\ vtara54@mail.ru \\ Irina V. Melik-Gaykazyan \\ Tomsk State University of Pedagogical Tomsk, Russia \\ Tomsk, Russia \\ melik-irina@yandex.ru \\ Oleg I. Zhukovsky \\ Tomsk State University of Control Systems and \\ Radioelectronics \\ Tomsk, Russia \\ zhuko154@gmail.com
}

\author{
Juliya V. Chernyshova \\ Tomsk State University, TSU \\ Tomsk, Russia \\ chernyshovajuliya@gmail.com \\ Anastasya V. Tarasenko \\ Education Department of Tomsk Town \\ Tomsk, Russia \\ ms.antara@mail.ru
}

\begin{abstract}
- the work is dedicated to research in the field of management of socio-economic systems, namely - the identification of statistical groups of respondents-managers by statistical and heuristic methods based on testing knowledge about the factors influencing the increase in productivity. Test were fulfilled in a framework of the universities course of management.

Keywords - educational technologies, management, crisis, productivity, nonlinear dynamics, respondents, statistical analysis, cluster analysis.
\end{abstract}

\section{GOALS AND OBJECTIVES OF THE STUDY}

The paradigm of nonlinear dynamics of socio-economic systems [1], which demonstrates sources of unstable states and rapid change of situations, has become generally accepted. It is especially relevant in Russian conditions, where the achievement of sustainable development is a promising goal.

Socio-economic systems in the market are open, nonlinear and non-equilibrium. In the self-organization of the elements of a nonlinear system, new functions and properties arise that are studied by synergetic - the science of the processes of self-organization in nonequilibrium systems.

Nonlinearity of systems leads to a multiplicity of real ways of development. As the system moves away from the equilibrium states, new solutions arise at the so-called bifurcation points. "Any description of a system undergoing bifurcation involves both deterministic and probabilistic aspects. Between the two points of successive bifurcations, deterministic laws are fulfilled, but fluctuations play an important role in the vicinity of the bifurcation points and they "select" the branch that the system will follow "[2].

In other words, in the behavior of systems, including socioeconomic ones, two fundamentally different levels can be distinguished: the level of deterministic behavior of the system and the level of stochastic changes.

The theory of catastrophes of mathematics is the study of spasmodic changes in the state of a system in response to a smooth change in external conditions. The theory of catastrophes, in a sense, is a generalization of the investigation of functions to an extremum in the case of many variables and is based on the theory of singularities of smooth mappings [3]. The latter makes many conclusions about the nature of socioeconomic processes geometrically clear.

In situations close to equilibrium states, the role of random factors is reduced, as a rule, to a minimum. Far from equilibrium, the system is "acted upon" by fluctuations, threatening its structure. Randomness pushes the system, which is in a crisis, critical state, to a new path of development, and once this path is chosen, determinism comes into force again.

The Russian managers are carriers, sources and 
eyewitnesses of the problems of Russian management. Therefore, one of the ways to identify problems in this area is to find out the opinion of the managers themselves about these problems, but not through direct questions, but finding out the views on some or other areas and provisions of modern theoretical management.

One of the most striking examples of situational management theory is the $3 D$ theory of organizational and managerial efficiency, which considers as a whole 1) the concrete situation, 2) the personality of the manager, and 3) the effectiveness of his leadership style. This theory is based on many well-known achievements of management thought, for example, on the Maslow hierarchy of needs [4], theories $X$, $Y$ [5] and $Z$ [6], managerial behavior models in different situations (situational management), leadership styles models .

The tool for survey managers in this study is the two groups of tests developed by Dr. Reddin, an adherent of the $3 D$ theory, tests for correctness of opinion and tests for preference. These tests are widely used abroad as a means of training in the preparation and retraining of managers, and in Scandinavian countries they have become virtually an educational standard. The authors of this study proposed and implemented an automated training system "Personal tests for managers" [7], the use of which allows for a short period to conduct a survey of a representative contingent of managers, as well as students of universities.

Respondents 'answers to the judgments are processed and analyzed to coincide with the test authors' estimates, individual scores and the average score for the group are determined, judgments are also ranked by the number of coincidences in the group with the evaluators of the test authors.

Interpretation of the results of the analysis is a demonstration of the main provisions of applied system analysis [8]: there is no one identical subject, because sets of models of subjects are different, but, despite the differences, in any two subjects in the sets of models something will necessarily coincide, because they interact with the same reality.

An analysis of the opinions of a large number of respondents may allow us to identify "stable" types of personalities of Russian managers, their "sustainable" priorities and determine the range of problems in which they express a reliable deviation from Western "standards" when expressing their opinions. The elucidation of the causes of these "deviations", their interpretation, and the identification of the role of the paradigm of nonlinear dynamics constitute the scientific significance of this study.

Thus, the relevance of the study is determined by the need to identify and formulate specific problems of modern Russian management in the light of the achievements of modern management thought and in the context of the nonlinear dynamics of socio-economic systems.

The goal of the study is to identify reliable "deviations" of the opinions of Russian managers on theoretical management issues from "Western" standards and to interpret these deviations, formulate problems and specifics of management styles of the respondents surveyed, to develop recommendations for improving the educational process, and develop the management theory in the context of nonlinear dynamics socio-economic systems.

Objectives of the research: 1) conducting an instrumental statistical survey of managers and students of universities, 2) interdisciplinary interpretation of survey results, 3) developing recommendations for improving the educational process, 4) developing the provisions of the theory of $3 D$ in the context of nonlinear dynamics of socio-economic systems.

\section{BASELINE DATA AND METHODS OF RESEARCH}

The test consists of 80 judgments. The respondent is invited to assess whether this statement is true or erroneous from his point of view (data in the nominal scale). Figures 1 and 2 show the forms for collecting test data. We present the results of the survey on the basis of information on the section "Communications in the organization", as an important factor in productivity.

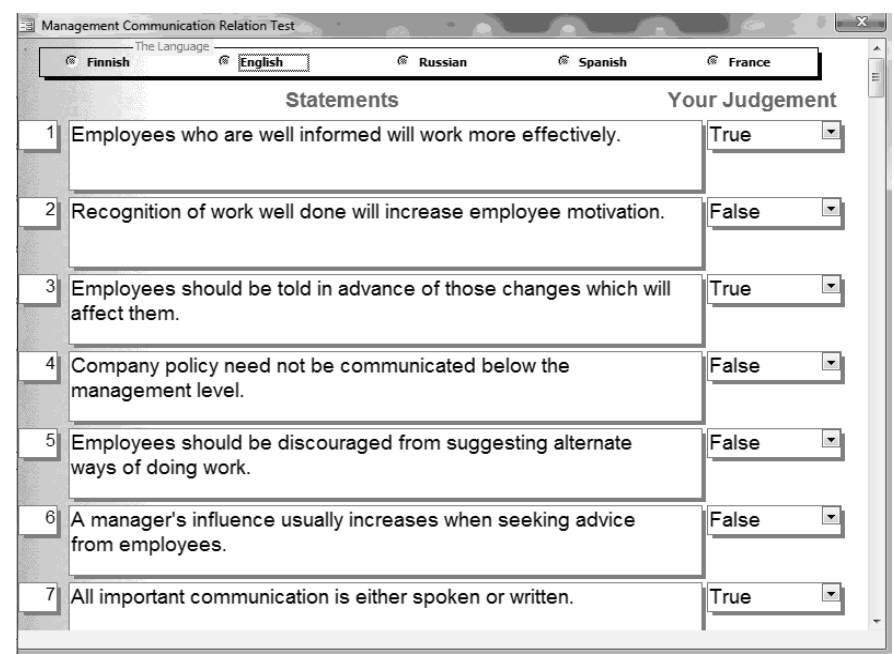

Fig.1. Example of a test for assessing the "correctness" of judgments 


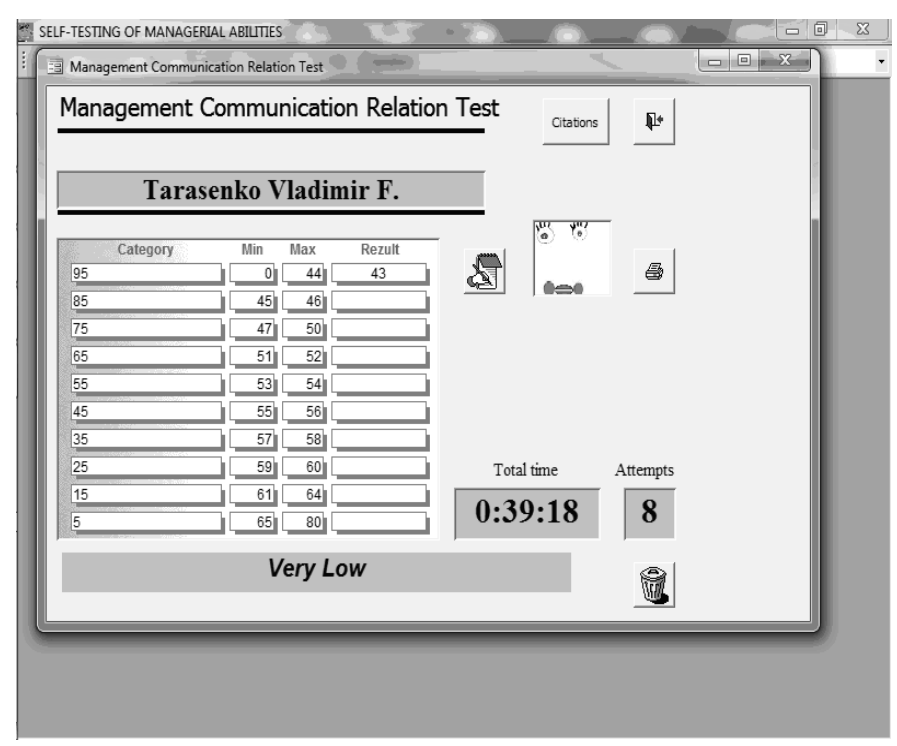

Fig.2. Example of the respondent's rating

The answers are reduced to a table whose rows correspond to the respondents, and the columns to the judgments. Let's designate the element of the table containing the estimate $i$-th respondent assessment of the $k$-th judgment through $X_{i, k}$, where $i=\overline{1, n}, n=2186$ - the number of respondents, $k=\overline{1, m}, m=80$ - the number of judgments in the test..

Among the respondents' answers were missing values, which makes analysis difficult. To fill in the missing values, we used the WANGA-N algorithm [9], which is applicable for data in a nominal scale.

After filling in the missing values, you can determine the number of "correct" answers (for the author of the tests [10]) for each respondent. The number of "correct" judgments is calculated as follows.

There is a sample of assessments of the authors of the test $\left\{A_{k}\right\}, k=\overline{1, m}$. Let

$$
\delta_{i}^{k}=\left\{\begin{array}{l}
1: X_{i, k}=\grave{A_{k}} \\
0: X_{i, k} \neq \grave{A_{k}}
\end{array}\right.
$$

Here $\delta$ is the Kronecker symbol, $i=\overline{1, n}, k=\overline{1, m}$. A "correct" evaluation of the respondent's judgment is an estimate that coincides with the assessment from the sample. Out of the 80 signs, a variable $L_{i}=\sum_{k=1}^{m} \delta_{i}^{k}$ was formed that characterizes the number of "correct" judgments of the $i$-th respondent.

In Fig. 3, judgments are ordered by the number of respondents who gave "correct" answers to them. It can be seen that there is not a single opinion that at least one respondent would not have assessed as the author of the tests.
Only one judgment was "correctly" evaluated by 353 respondents. All other judgments were judged "correctly" by a large number of respondents. One judgment was judged "right" by 2,169 respondents out of 2,186. All this demonstrates the positions of system analysis that each subject has his own unique set of models on the basis of which he makes his assessments, and that two different subjects in the set of models necessarily have something to match.

As analytical tools, statistical analysis, cluster analysis, pattern recognition [11], test theory [13] was used. The results obtained and the analysis techniques are described in [12].

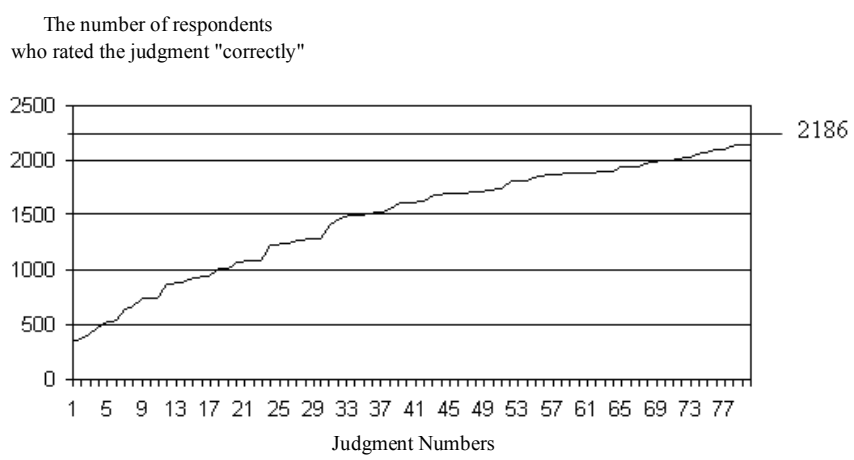

Fig. 3. Streamlining of judgments depending on the number of respondents who rated the judgment "correctly"

The variable $\left\{L_{i}\right\}$ was used to perform a cluster analysis [9] with the aim of identifying natural groupings in the data.

As a metric of difference (to calculate the distance between objects), the degree of proximity between the $i$-th and $j$-th objects was calculated by the formula: $D\left(L_{i}, L_{j}\right)=\left|L_{i}-L_{j}\right|$.

As a method of cluster analysis, the "far-neighbor" method was used, since it is most conducive to the isolation of isolated groups, due to the fact that the degree of proximity is estimated from the distance between the most distant objects of the clusters.

The artificial classification proposed by the author of the tests [10] differs significantly from the one obtained in the clustering process (Fig. 4, 5), except for the right boundary for "a very high level of knowledge". 


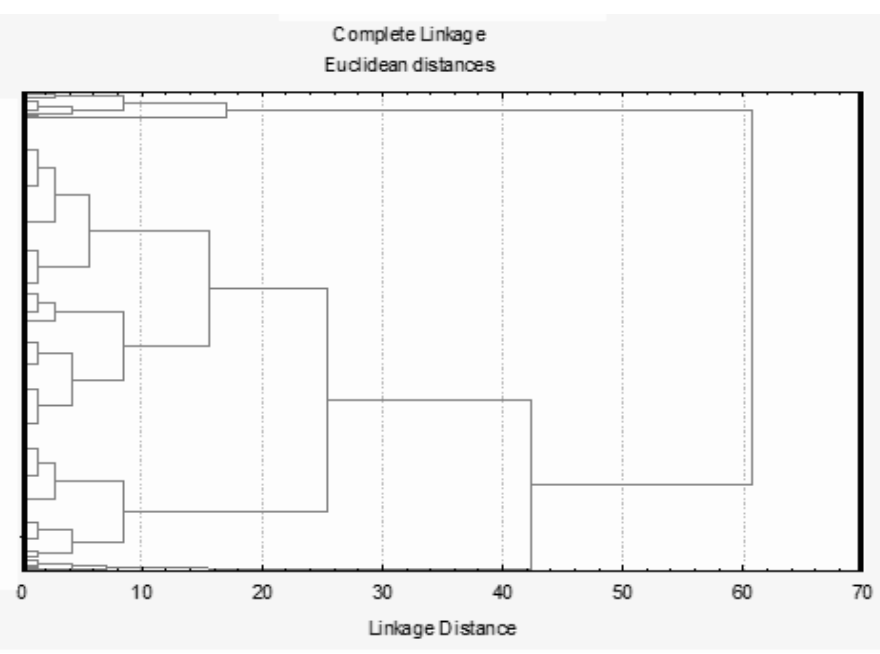

Fig.4. Dendrogram of cluster fusion

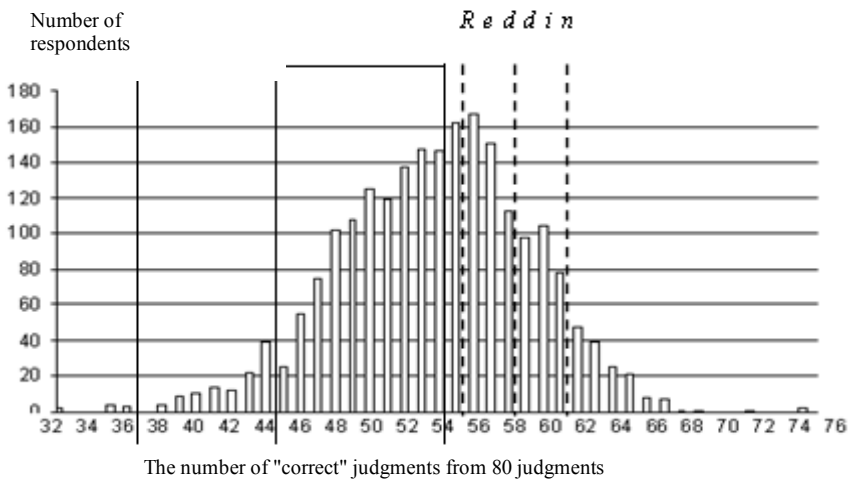

Fig.5. "Natural" (solid vertical lines) and artificial (dashed vertical lines) classification of respondents

\section{CONCLUSION}

The novelty of the research is that 1) the methods of situational management are considered in the context of the non-linear dynamics of socio-economic systems, 2) an instrumental statistical survey of a representative group of responding managers to determine their views on knowledge of types of situations, knowledge of personal qualities, ways of carrying out reforms, knowledge of ways to achieve effectiveness in different types of situations, 3) identify the relationship between groups of respondents with different styles of management.

The processing of collected data was carried out, a statistical study of management personnel, as well as students of higher education institutions - future managers from the positions of situational management, was conducted. The study is aimed at developing recommendations for improving the teaching of the discipline "Management Theory".

The results described above were obtained on a sample of 2186 by one test.

Further studies suggest the use of five tests with more than
5,000 respondents. The data was collected for 15 years. This allows studying the structural changes in the collected data at different time periods, including periods of crises.

\section{REFERENCES}

[1] Melik-Gaikazyan I.V. Methodology for modeling non-linear dynamics of complex systems / I.V. Melik-Gaikazyan, M.V., Melik-Gaikazyan, V.F. Tarasenko. - Moscow: FIZMATLIT, 2001. - 272 p.

[2] Prigogine I.R. Order out of chaos. A new dialogue between man and nature / I.R. Prigogine. - Moscow: Progress, 1986. - 432 p.

[3] Arnold V.I. The theory of catastrophes - Moscow: Izd-vo MGU, 1990. $128 \mathrm{p}$.

[4] Abraham H. Maslow. Motivation and Personality (2nd ed.) N.Y .: Harper \& Row, 1970.

[5] MacGregor D. The Human Side of Enterprise. / D. MacGregor - The MacGrow-Hill Companies, 2006. - 403p.

[6] Ouchi U. Methods of production organization: Japanese and American approaches. / U. Ouchi - Moscow: Nauka, 1993. 230p.

[7] Tarasenko V.F., Tarasenko F.P. The approach to management training, focused on the use of methodology and technology of system analysis. Materials of international scientific-practical. Conf. "System Analysis in Design and Management" - St. Petersburg: 2003. 2p.

[8] Tarasenko F.P. Applied Systems Analysis (Science and the Art of Problem Solving): A Textbook. / F.P. Tarasenko - M: Knorus - 2017. $322 p$.

[9] Zagoruiko N.G. Applied methods of data and knowledge analysis / N.G. Zagoruiko - Novosibirsk: Izd-vo Institute of Mathematics, 1999. - 268p.

[10] Reddin W.J. Tests for the output-oriented manager. W.J.Reddin London, Kogan Page Limited, 1991, 307p.

[11] Mendel I.D. Cluster analysis. / I.D. Mendel - Moscow: Finance and Statistics, 1988. 176p.

[12] Tarasenko V.F. To the identification of groups of managers / The scientific and practical journal "Problems of management in social systems" / V.F. Tarasenko, O.V. Blinova. - Tomsk, Izd-vo TSU. T.2, Issue 4, 2011, pp. 22-29.

[13] Crocker L., Algina J. Introduction to Classical and Modern Test Theory. Cengage Learning, 2006. - 527 p. 